\title{
AVALIAÇÃO DE LOCAIS COM POTENCIALE/OU UTILIZADOS NO TURISMO AMBIENTAL NA CIDADE DE CAMPO GRANDE-MATO GROSSO DO SUL
}

JAFAR, Andrea Cadija Duarte; OLIVEIRA, Ademir Kleber Morbeck*; BONONI, Vera Lúcia Ramos; MASCARÓ, Lúcia Elvira Alícia Raffo. Universidade Anhanguera-Uniderp. Programa de Pós-Graduação em

Meio Ambiente e Desenvolvimento Regional. Rua Alexandre Herculano, 1400 - CEP 79037-280, Campo Grande, MS, Brasil. *E-mail: akmorbeck@ hotmail.com.

\begin{abstract}
Resumo
A cidade de Campo Grande possui áreas com atrativos naturais que podem ser utilizados para a prática do turismo ambiental. Porém, a avaliação desses locais, por meio de critérios de potencial turístico, indica que a maior parte das áreas não possui infraestrutura adequada para a recepção dos visitantes ou sua estrutura física está deteriorada, e apenas cinco áreas possuem condições adequadas (alto potencial).
\end{abstract}

PalaVras-chave: Áreas verdes; Parques urbanos; Turismo ecológico.

\begin{abstract}
The city of Campo Grande has natural attractions that can be used in the so-called environmental tourism. However, most areas with such potential do not have proper infrastructure to shelter visitors or their physical structure is deteriorated. The critical evaluation of these places using criteria of tourist potential indicates that most of the areas of the city do not have adequate infrastructure for the reception of the visitors or their physical structure is spoiled and only five areas have adequate conditions (high potential).
\end{abstract}

KEYWORDS: Green areas; Urban parks; Ecological tourism. 


\section{INTRODUÇÃ̃o}

A cidade de Campo Grande é considerada umas das cidades brasileiras com melhor qualidade de vida, com ruas e avenidas, largas e arborizadas, além de muitos parques e praças, que propiciam um ambiente agradável, que muitas vezes lembra as cidades de interior. Em 1977, com a divisão do Estado de Mato Grosso, tornou-se a capital do Estado de Mato Grosso do Sul e passou por um processo acelerado de urbanização e crescimento, tornando-se um polo de atração para pessoas de outras cidades e regiões (CAMPO GRANDE, 1999). Esse processo, como em outras grandes cidades, criou problemas urbanísticos e ambientais e a qualidade de vida em determinadas regiões caiu, surgindo favelas e outras habitações de baixa qualidade em determinados locais, normalmente associados a fundos de vale, por exemplo (ALMEIDA NETO et al., 2011).

Porém, mesmo com os problemas surgidos, a cidade continua sendo um polo de atração regional, com uma forte presença econômica no setor secundário e terciário, o que tambématrai empresários e outras pessoas ligadas a diferentes ramos da economia, além de uma forte presença no ramo de eventos, tais como simpósios, encontros e congressos.

Dessa maneira, a cidade atrai turistas, que permanecem na região por um determinado período e se dividem em dois grandes grupos: turismo de participação em congressos, eventos em geral ou negócios; e turismo ambiental, com destino ao Pantanal ou à região da Serra da Bodoquena - Campo Grande, por possuir aeroporto com capacidade de receber aviões de grande porte, além de ser ponto de passagem da rodovia BR- 262, que se liga a essas regiões, tornou-se umpolo receptor (transitório) de turistas que se dirigem a esses locais. A maior parte desses visitantes tem um tempo médio de permanência na cidade de dois a três dias, apesar de a cidade possuir locais com atrativos naturais que podem ser utilizados para prática esportiva, além de áreas para visitação e contemplação passiva, como parques e reservas.

Esse tipo de turismo, relacionado à natureza, cresce a uma taxa de 10 a $30 \%$ ao ano, o que mostra que as pessoas cada vez mais estão em busca de áreas naturais para o lazer (CEBALLOS-LASCURÁIN, 1993; LINDBERG e HAWKINS, 2001). Segundo Ruschmann (2009), nas últimas décadas, as pessoas estão procurando um maior contato com a natureza, através da "busca do verde" e da fuga dos tumultos dos grandes conglomerados urbanos, tentando recuperar o equilíbrio psicofísico em contato com os ambientes naturais durante seu tempo de lazer. Abusca desse contato com a natureza é chamada de questão de amenidade.

Apesar dos atrativos naturais da cidade, a maioria da população continua desconhecendo esses locais. Porém, para que o usuário dessas áreas ligadas à natureza e ao lazer possa ser adequadamente recebido, é necessário conciliar o conhecimento e a divulgação dos pontos em questão e, em alguns casos, adaptar sua infraestrutura. Essa melhoria propiciaria uma maior permanência dos turistas na região, gerando divisas e também atraindo moradores das cidades vizinhas e da própria capital, que não conhecem esses pontos por falta de informação ou pela pouca divulgação de suas belezas naturais. Portanto, um planejamento de um roteiro de ecoturismo na cidade poderá ser viável, desde que sejam feitas algumas adequações.

Dessa maneira, o objetivo deste trabalho foi fazer o levantamento dos locais com potencial para o ecoturismo em suas diferentes vertentes, avaliando o potencial das áreas e verificando a infraestrutura existente para atender os usuários.

\section{Material e MÉTOdos}

A cidade de Campo Grande está localizada na Bacia do Rio Paraná, no centro do Estado de Mato Grosso do Sul, nas coordenadas geográficas de latitude $20^{\circ} 28^{\prime} 11,775^{\prime \prime}$ e longitude 54³7‘24,04960", com população em torno de 800 mil habitantes (CAMPO GRANDE, 1999). Para o desenvolvimento da pesquisa, foram escolhidas 14 áreas que são utilizadas ou constam do plano diretor da cidade como pontos de interesse ambiental, mapeadas de acordo com suas posições em relação ao centro urbano através do programa Google Earth (Figura 1). 


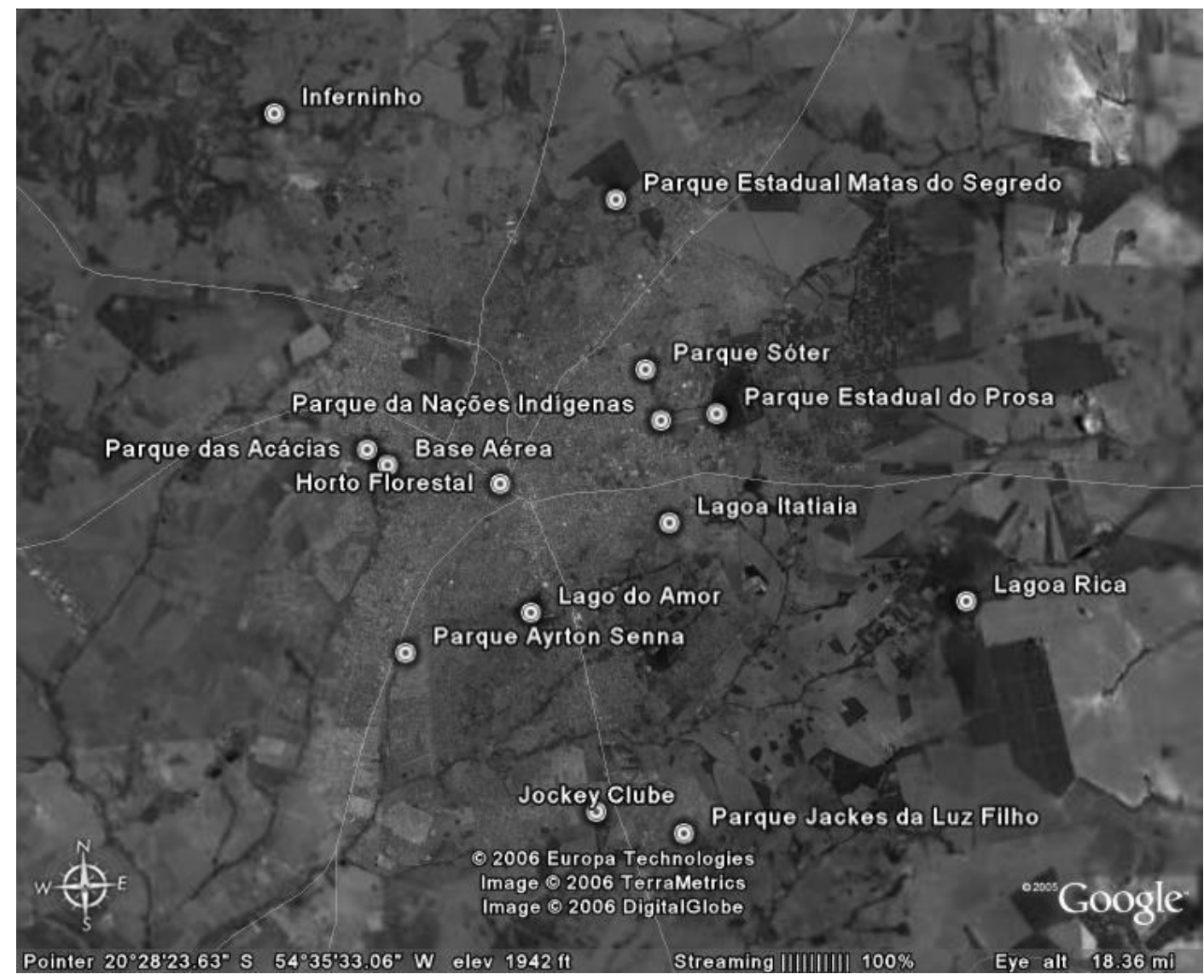

Figura 1 - Recorte de uma imagem de satélite da cidade de Campo Grande, Mato Grosso do Sul, com os pontos turísticos propostos.

Fonte: Google Earth.

Os locais em estudo foram descritos e classificados de acordo com o Plano Diretor de Campo Grande, onde se encontram as áreas especiais de interesse ambiental e urbanístico (CAMPO GRANDE, 1998).

A avaliação do potencial turístico foi feita por meio da criação de uma tabela de potencial turístico, adaptando-se conceitos de Ignarra (2003), Beni (2004) e Cunha (2006), em que os atrativos foram avaliados de 0,0 a 10,0, sendo de 0,0 a 2,0 ruim; de 2,1 a 4,0 regular; de 4,1 a 6,0 médio; de 6,1 a 8,0 bom; e de 8,1 a 10,0 ótimo, com a elaboração de uma média para cada atração, através de visitas in loco nas áreas de estudo e informações obtidas em órgãos públicos municipais e estaduais, sendo avaliados os seguintes parâmetros: $\checkmark$ Acesso (inclui condições da estrada ou rua, pavimentação, distância do centro, se a propriedade é pública, privada ou área militar);

$\checkmark$ Lanchonete/restaurante (presença ou ausência, diversidade de oferta de produtos, além de estado de conservação e aparência);

$\checkmark$ Delimitação de limites (área cercada e o estado de conservação de sua cerca ou outro tipo de limite);

$\checkmark$ Segurança (presença de guardas ou outro tipo de segurança);

$\checkmark$ Administração e proteção do local (existência de local construído para administração da área, se possui posto para guarda patrimonial ou polícia militar, sendo utilizado ou não, além da conservação dos mesmos); 
$\checkmark$ Sanitários e pontos de oferta de água potável (estado de conservação, localização e quantidade no local, levando-se em consideração o tamanho da área);

$\checkmark$ Auditório, teatro ou espaço coberto para eventos que atendam a população e seu estado de conservação;

$\checkmark$ Área de esportes (inclui quadra para atividades, tais como futebol de salão ou vôlei, campo de futebol, equipamento para atividades físicas, tais como barras ou prancha para abdominais, pista para cooper ou caminhada, entre outros, além do estado de conservação);

$\checkmark$ Área de recreação (inclui área de piquenique ou local para observação/contemplação, tais como bancos ou gramados, piscinas ou outro tipo de local para recreação aquática, equipamento de recreação para crianças, tais como parquinhos, além da conservação dos equipamentos ou locais);

$\checkmark$ Lago e/ou espelhos d'água (áreas para contemplação da paisagem, prática de esportes e/ou lazer do usuário);

$\checkmark$ Telefone público (número de aparelhos, localização, considerando-se o tamanho da área, além da conservação dos mesmos);

$\checkmark$ Estacionamento (existente, pavimentado ou não, arborizado, além do número de vagas e estado de conservação);

$\checkmark$ Iluminação (presente em toda área, sem luminárias queimadas ou desligadas);

$\checkmark$ Vegetação (com ou sem presença de vegetação nativa e projeto de paisagismo que ofereçam conforto visual e ambiental aos visitantes ou ausência de vegetação de porte - árvores).

\section{RESUltados E DISCUSSÃo}

Foram avaliados 14 locais, de acordo com suas respectivas características:

a) Parque Estadual Matas do Segredo

Possui 179,58 hectares de vegetação composta de Cerrado, cerradão e matas decíduas em processo de regeneração na região norte do município, próximo aos Bairros Mata do Jacinto, Nova Lima e Coronel Antonino. No local, encontra-se a nascente do córrego Segredo; por enquanto, não está aberto à visitação e a única atividade pública existente é voltada para educação ambiental, civismo e atividades militares com jovens que residem nos bairros próximos e frequentam o local no período vespertino, quando têm aulas e são servidos almoço e lanche.

Avaliação: acesso pavimentado, mais de $10 \mathrm{~km}$ do centro, propriedade pública, local demarcado com portaria, com segurança, sede de administração, sanitários, local para reuniões, vegetação nativa em bom estado e presença de fauna, sem local para atividades físicas ou recreação, telefones públicos ou estacionamento, iluminação precária e trilhas não sinalizadas. Média - 2,9.

b) Área de Preservação Ambiental do Ceroula (Inferninho)

Situado na região da APA do Córrego Ceroula, a $25 \mathrm{~km}$ do centro de Campo Grande, saída para a cidade de Rochedo. Compreende a mata ciliar situada dentro do vale formado pelo córrego Cerroula até 500 (quinhentos) metros após a cachoeira do local denominado "Inferninho" (queda livre de $35 \mathrm{~m}$ ). Está inserido numa propriedade particular, possuindo características de fauna e flora fundamentais à conservação da biodiversidade regional, altamente modificada na região.

As atividades mais praticadas no local são o rapel, mountain bike e o turismo relacionado a trilhas, tirolesa e lazer em geral, como banhos nas cachoeiras e contemplação da paisagem, porém sem planejamento e manejo dos impactos decorrentes da visitação. Parte da área, principalmente o vale formado após a cachoeira do Inferninho, poderia ser transformada em uma reserva biológica ou um parque municipal, propiciando-se o cuidado e a manutenção do local, com equipamentos de infraestrutura básicos para atender seus usuários.

Avaliação: rodovia de acesso não pavimentada e em mau estado de conservação, mais de $10 \mathrm{~km}$ do centro, propriedade particular, sem local de recepção, limites definidos, segurança, local para recepção e descanso, telefone, estacionamento, sanitários, iluminação; presença de vegetação natural e fauna. Média-nota 0,9 . 
c) Parque Estadual do Prosa (antiga Reserva Ecológica do Parque dos Poderes)

Área da nascente do córrego Prosa, no Parque dos Poderes, área administrativa do governo estadual, hoje conhecida como Parque Estadual do Prosa. É um dos últimos fragmentos de Cerrado, Floresta Decídua e matas de galeria na área urbana da capital, além de uma das únicas unidades de conservação estaduais abertas para visitação. A vegetação encontra-se em processo de regeneração bastante avançado, pois a área sofreu intervenções agropecuárias no passado, através de retirada de parte da vegetação nativa.

Como atrativos, possui trilhas interpretativas, com monitores aptos a acompanhar os visitantes e a propiciar-lhes um passeio interessante, passando por pequenas pontes e deques ao longo dos córregos Joaquim Português, Desbarrancado e Prosa. Possui um centro de visitantes que mostra, por meio de um vídeo, um pouco do passado de Campo Grande e dos conceitos atuais de proteção dos recursos naturais, além do cantinho do Prosa, um espaço de arte. No local também está localizado o CRAS, Centro de Reabilitação de Animais Silvestres, normalmente não aberto à visitação pública.

Como sugestões para melhoria do local, uma trilha alternativa com entrada pela Avenida Mato Grosso e um melhor acompanhamento dos turistas, evitando a saída da trilha original, o que possibilita a degradação das margens, ampliando desnecessariamente a trilha. Dentro do parque não há a disponibilidade de serviços como lanchonete e venda de artesanato local, que poderiam gerar renda e emprego, além do conforto ao usuário.

Avaliação: rodovia de acesso pavimentada, menos de $5 \mathrm{~km}$ do centro, área pública, presença de fauna e vegetação nativas, com limites definidos, segurança, sede, sanitários, área de lazer, telefone público, iluminação; sem local para reunião e estacionamento. Média - 5,0.

\section{d) Lago do Amor}

O lago é formado pelo represamento do córrego Segredo na área do campus da Universidade Federal do Mato Grosso do Sul - UFMS. Possui um potencial enorme para o turismo ambiental, pois se situa ao lado da reserva biológica da UFMS, formada por vegetação de mata de galeria e vereda em processo de regeneração. Porém, o local está interditado para passeios de pedalinhos, por exemplo, pois a água está poluída, já que parte do esgoto da região é descartada no córrego. O local é constantemente tomado por plantas aquáticas, que cobrem toda a lâmina d'água e produzem um local propício para a criação de pernilongos e outros insetos, que trazem desconforto aos moradores próximos, além de a matéria orgânica produzida, quando em processo de decomposição, gerar odor desagradável, além de outros problemas ambientais.

A região até poucos anos era ponto referencial de turismo na cidade de Campo Grande e, atualmente, é uma lagoa degradada. Poderia ter seu valor resgatado, voltando a ser um ponto turístico da capital sul-matogrossense, através do tratamento de esgoto. Atualmente foi construída uma área de contemplação próxima a uma das margens, combancos na calçada e iluminação.

Avaliação: área pública, menos de $5 \mathrm{~km}$ do centro com acesso asfaltado, presença de fauna e flora, lanchonete, limites, local de recreação, telefone, iluminação, segurança parcial e área para atividade física, através de caminhada. Média - 5,7.

\section{e) Área da Lagoa Itatiaia}

Localizada no Bairro Tiradentes, a lagoa foi urbanizada em dezembro de 2003, recebendo calçamento e iluminação ao redor da área alagada; em 2011 recebeu equipamento para atividades físicas, a chamada academia ao ar livre. A área enfrenta problemas de lixo nas margens e a vegetação ainda está se recompondo, pois o local foi degradado anteriormente, recebendo, inclusive, restos de obras de construção.

Avaliação: área pública, menos de $5 \mathrm{~km}$ do centro da cidade com acesso asfaltado, presença de fauna e flora, local de recreação, lanchonete, telefone público, iluminação; segurança parcial e sem sanitários, estacionamento ou local para reunião. Média-4,5. 
f) Área da Lagoa da Base Aérea

É citada como uma das áreas especiais de interesse ambiental, localizando-se dentro da Base Aérea de Campo Grande, na Avenida Duque de Caxias. Porém, o curso d'água que abastecia a lagoa foi desviado por duas vezes por motivos de construções na área e a lagoa secou. Mas ainda existe na área uma reserva ecológica, onde é possível visualizar a flora local e encontrar animais como quatis, tatus e araras. Dificilmente, no entanto, a área pode ser incluída num roteiro de turismo, pois é uma área militar e a visitação é mais restrita.

Como sugestão, a transformação da reserva em parque estadual ou municipal, passando o controle para o poder público civil, o que permitiria a utilização do local de maneira mais democrática, além de garantir, em teoria, sua manutenção.

Avaliação: área pública militar, menos de $5 \mathrm{~km}$ do centro com acesso asfaltado, presença de fauna e flora diversificada, telefone, iluminação e segurança; sem áreas para atividade física ou recreação, lanchonete, sanitários, estacionamento ou local para reunião. Média - 2,8.

g) Área do Jockey Club de Campo Grande (Hipódromo Aguiar Pereira de Souza)

O hipódromo está situado próximo à saída para São Paulo (BR-163), onde ocorrem corridas esporádicas. Todos os dias, no período vespertino, os cavalos treinam na pista. Porém, o local precisa de alguns cuidados em relação à vegetação e limpeza. Também falta sinalização para o acesso.

Avaliação: área particular, mais de $10 \mathrm{~km}$ do centro com acesso asfaltado, presença de animais, telefone, iluminação, estacionamento, vegetação, sede, sanitários; sem segurança, áreas para atividade física ou recreação, lanchonete. Média - 4,1.

h) Balneário Lagoa Rica

A lagoa está situada na fazenda pertencente à família Metello, na área rural do município, a $16 \mathrm{~km}$ do centro urbano, próximo a BR-262. É utilizada para prática de esportes náuticos sem motores, desde a década de 1960.
No local, há trilhas para a prática de MotoCross esse uso levou à retirada de vegetação nativa, descobrindo o solo, apresentando erosão laminar e falta de segurança em alguns pontos. $\mathrm{O}$ local também possui campo de areia para prática de vôlei e futebol, piscinas, churrasqueiras e um parque infantil em condições precárias. Para que o local atenda à demanda turística, é necessária uma reforma em geral das instalações.

O local é de interesse público e poderia ser desapropriado para sua preservação, sendo transformado em um parque municipal, pois na área existem buritizais e áreas de Cerrado, remanescentes de vegetação original, além de nascentes importantes para a preservação dos recursos hídricos. Atualmente existe um projeto para a transformação do local em área pública.

Avaliação: não possui acesso pavimentado (estrada em mau estado de conservação), mais de $10 \mathrm{~km}$ do centro, propriedade particular, portaria onde se cobra taxa de visitação, com fauna e flora, limites, sede, sanitários, equipamento de recreação, telefone, iluminação; segurança parcial. Média - 5,2.

i) Parque das Nações Indígenas

O local possui 116 hectares e está localizado em uma posição geográfica privilegiada - altos da Avenida Afonso Pena, que possibilita o fácil acesso de moradores provenientes dos mais diversos bairros da capital, sendo circundado por uma parte nobre da cidade, com belas residências, centros comerciais, hospital e pavilhão de feiras e exposições, assim como pelo centro político e administrativo do Estado, o Parque dos Poderes.

Avaliação: área pública, menos de $5 \mathrm{~km}$ do centro com acesso asfaltado, presença de fauna local, oferecendo uma adequada infraestrutura completa para a prática do lazer e esporte, museus, restaurante, estacionamento, lanchonete, concha acústica, sanitários, policiamento, pista para caminhadas, skate, patins e um grande lago artificial, resultado do represamento do córrego Prosa, com deque para a contemplação da paisagem, porém com problemas de assoreamento. A vegetação do parque é antropizada, 
com espécies típicas da região intercalada com exóticas. Uma parte das espécies está catalogada, com informações ao usuário; outras não possuem placas informativas. Média-8, 1 .

j) Parque Jacques da Luz Filho (Parque das Moreninhas)

Possui 43 hectares e localiza-se no Bairro Moreninha II, local com aulas de balé, dança de salão, capoeira, natação, pintura em tela e teatro. No local, frequentemente, tem-se apresentações, shows, festas comemorativas e outros eventos para confraternização dos usuários.

Avaliação: área pública, mais de $10 \mathrm{~km}$ do centro com acesso asfaltado, possuindo uma boa infraestrutura, com banheiros públicos, quadras poliesportivas (cobertas e ao ar livre), piscinas, pista de caminhadas, salas para aula de teatro e dança com camarim, espaço para eventos coberto, cantina e estádio de futebol (Toca da Onça), além de telefone, iluminação e segurança. A infraestrutura do parque é parcialmente adequada, mas faltam placas de sinalização para se chegar ao local, lanchonete, sanitários, estacionamento; a vegetação é pobre e a presença de fauna é escassa. Média - 7,7.

\section{k) Parque Ayrton Senna}

Área de 7 hectares, o parque está localizado no bairro Aero Rancho, às margens do córrego Segredo, com construções em estilo moderno, possuindo programa e projetos focados nas atividades esportivas.

Avaliação: área pública, menos de $5 \mathrm{~km}$ do centro com acesso asfaltado, possuindo como infraestrutura, banheiros públicos (manutenção inadequada, com vasos sanitários quebrados), telefone, segurança, quadras poliesportivas, piscinas (fora de uso por falta de manutenção), parque infantil, pista de caminhada, sala de arte, de capoeira, espaço para eventos coberto e cantina (desativada) e iluminação precária, além da falta de placas de sinalização para o acesso. Além disso, a vegetação arbórea e/ou arbustivo-herbácea não existe na maior parte da área; também falta estacionamento. Média-7,0.

\section{1) Parque das Acácias}

Área de 42 hectares em um local privilegiado, numas das principais entradas de Campo Grande, no acesso para o Pantanal sul-mato-grossense, em frente à Base Aérea e do Aeroporto Internacional. O local foi decretado como parque e está em processo de implantação.

Avaliação: área pública, menos de $5 \mathrm{~km}$ do centro com acesso asfaltado, sem local de recreação, telefone, iluminação parcial, vegetação, segurança, áreas para atividade física, lanchonete, sanitários; estacionamento ou fauna local. Média - 0,7.

m) Parque Florestal Antônio de Albuquerque (Horto Florestal)

Situado na área central da cidade, possui um elaborado projeto paisagístico, em estilo contemporâneo. O local possui segurança e uma boa infraestrutura, que frequentemente passa por manutenção, atendendo perfeitamente seus usuários, pois é mantido em parceria com organizações, tal como o SESC, o que propicia a manutenção adequada para o local, além de segurança.

Também oferece cursos e oficinas, sendo aberto à visitação gratuita de terça-feira a domingo e às segundasfeiras é fechado para manutenção, com exceção da biblioteca, que é aberta no período vespertino. Outro grande atrativo do parque são as atividades voltadas para a terceira idade, público este que aumenta frequentemente, procurando uma melhor qualidade de vida e lazer, pois o local possui umcentro de convivência para os idosos (Centro João Nogueira Vieira).

Avaliação: área pública central com acesso asfaltado, local de recreação, telefone, iluminação, segurança, áreas para atividade física, pista de caminhada com vegetação catalogada, lanchonete, sanitários, local para eventos e biblioteca; sem estacionamento ou presença de fauna significativa. Média-8,9.

\section{n) Parque Sóter}

Formado pela bacia do córrego Sóter, no início da Avenida Via Parque, área norte da cidade. Foi criado 
para solucionar os problemas de erosão que existiam em determinados pontos da região que formavam grandes voçorocas, ameaçando a nascente do córrego Sóter e o arruamento da área.

Avaliação: área pública, localizada a menos de 5 $\mathrm{km}$ do centro com acesso asfaltado, telefone, iluminação, estacionamento, segurança, sanitários; pequena presença de fauna, quadras esportivas, parque infantil, pistas de skate, de caminhada, espaços para descanso e lazer, auditório, além da área administrativa do parque. No local foi detectada a falta de serviços como lanchonete e loja para venda de produtos locais (artesanato), já que dispõe de um auditório, que atrai público quando da realização de eventos. Também é necessária a catalogação das espécies vegetais existentes, como forma de educação ambiental voltada aos usuários, além do controle dos processos de erosão e do assoreamento do lago do local. Média - 7,3.

\section{Conclusão}

A maior parte das áreas com potencial turístico da cidade não possui infraestrutura adequada para a recepção dos visitantes ou sua estrutura física está deteriorada. Outros não possuem placas de sinalização e são desconhecidos, tanto dos moradores como dos visitantes da cidade.

Apenas cinco áreas possuem condições adequadas (alto potencial): Parque das Nações Indígenas $(8,1)$, Parque Jacques da Luz Filho $(7,7)$, Parque Ayrton Senna (7,0), Parque Florestal Antônio de Albuquerque $(8,9)$ e Parque Sóter $(7,3)$, com infraestrutura apropriada, acesso em boas condições e equipamentos com condições para atender o usuário.

Também cinco locais apresentam potencial médio, onde precisam ser feitas algumas alterações: Parque Estadual do Prosa (5,0), Lago do Amor (5,7), Jockey Clube $(4,1)$, Lagoa Itatiaia $(4,5)$ e Balneário Lagoa Rica $(5,2)$. Cada um com suas particularidades, não alcançaram boa média pelo fato de não oferecerem infraestrutura que outros locais oferecem ao público. No caso da Lagoa Rica, as instalações e os equipamentos de recreação, em condições precárias, precisam de reforma.

Com médias baixas: Parque Estadual Matas do Segredo $(2,9)$, Área de Preservação do Inferninho $(0,9)$, Área da Lagoa da Base Aérea $(2,8)$ e Parque das Acácias $(0,7)$. No caso do Parque Estadual Matas do Segredo, a média foi baixa pelo fato do local ainda não ter implementado seu plano de manejo. Aárea de preservação do Inferninho está distante do centro urbano, com acesso não pavimentado e sem infraestrutura. Já o Parque das Acácias está sendo implantado e a área da lagoa da base tem problemas de acesso.

A cidade ainda não possui condições de atrair e manter turistas voltados ao turismo ambiental em razão da pequena oferta de locais com alto potencial turístico.

\section{Agradecimentos}

Ao prof. dr. Sílvio Jacks dos Anjos Garnés, à turismóloga Flávia Néri e à engenheira Vera Acceturi (secretária de Meio Ambiente), pela colaboração na elaboração das imagens de satélite, materiais e informações. À CAPES pela bolsa de estudos concedida.

\section{REFERÊNCIAS}

ALMEIDA NETO, J.V.; OLIVEIRA, A.K.M.; BONONI, V.L.R. Atuação do Conselho Municipal do Meio Ambiente em Campo Grande-MS: Licenciamento Ambiental. Revista Uniara, v. 14, n. 1, p. 158-168, 2011.

BENI, M.C. Análise estrutural do turismo. 10 ed. São Paulo: SENAC, 2004. 513p.

CAMPO GRANDE. Instituto Municipal de Planejamento Urbano e Meio AmbientePLANURB. Legislação municipal de interesse ambiental de 1977 a janeiro de 1997. Campo Grande: EDUFMS, 1998.448p.

\section{CAMPO GRANDE. 100 anos de construção.} Campo Grande: Matriz Editora, 1999. 420p. 
CEBALLOS-LASCURÁIN, H. Ecotourism in the third world: problems for sustainable tourism

development. Tourism management, v. 14, n. 2, p. 85-90, 1993.

CUNHA, L. Economia e política do turismo.

Lisboa: Verbo, 2006. 488p.

IGNARRA, L.R. Fundamentos do turismo. São
Paulo: Thompson, 2003. 930p.

LINDBERG, K.; HAWKINS, D.E. Ecoturismo, um guia para planejamento e gestão. São Paulo: SENAC, 2001. 292p.

RUSCHMANN, D. Turismo e planejamento sustentável: a proteção do meio ambiente. São Paulo: Papirus, 2009. 199p. 